\title{
Uji Ketahanan Beberapa Varietas Padi Sawah Terhadap Hama Kepinding Tanah (Scotinophara coarctata) Di Rumah Kasa
}

Resistance Test Of Rice Varieties Against Rice Black Bug (Scotinophara coarctata) In The Screen House

\section{Annisa Audina Purba, Irda Safni*, dan Maryani Cycu Tobing}

Program Studi Agroteknologi, Fakultas Pertanian USU, Medan 20155

*Coressponding author: irda@usu.ac.id

\section{ABSTRACT}

Rice Black Bug (Scotionophara coarctata) is one of important rice pests that attack all growth stages of rice. This research was aimed to the most determine resistance of some varieties of black bug (S. coarctata). This research was aimed to determine resistance of several rice varieties against rice black bug ( $S$. coarctata). This research was conducted in the Laboratory of Pest and in the Screen House Faculty of Agriculture, University of Sumatera Utara in Medan, from August to December 2017. This study used a Randomized Block Design (RBD) factorial with four replications. The first factor was rice varieties (Ciherang, Inpari 32 and IR 64) and the second factor was the number of pest introductions (2, 4, and 6 pairs). The results showed that all rice varieties (Ciherang, Inpari 32 and IR 64) were categorized as scale of 1 (resistant). The final rice black bug population was 19, 18, and 16 for Ciherang, IR64 and Inpari 32 respectively.

Keywords: Resistance, rice varieties, Scotinophara coarctata, rice black bug.

\begin{abstract}
ABSTRAK
Kepinding tanah (Scotionophara coarctata) merupakan salah satu hama penting tanaman padi yang menyerang pada semua tahapan pertumbuhan tanaman padi. Penelitian ini bertujuan untuk menguji ketahanan beberapa varietas padi sawah terhadap kepinding tanah ( $S$. coarctata). Penelitian ini bertujuan untuk menguji ketahanan beberapa varietas padi sawah terhadap kepinding tanah $(S$. coarctata). Penelitian ini dilaksanakan di Laboratorium Hama dan Rumah Kasa Fakultas Pertanian Universitas Sumatera Utara Medan, mulai bulan Agustus sampai dengan Desember 2017. Penelitian ini menggunakan Rancangan Acak Kelompok (RAK) faktorial dengan empat ulangan. Faktor pertama adalah varietas padi (Ciherang, Inpari 32 dan IR64) dan faktor kedua jumlah introduksi hama $(2,4$, dan 6 pasang) Hasil penelitian menunjukkan bahwa ketiga varietas (Ciherang, Inpari 32 dan IR64) tergolong skala 1 (tahan) dengan populasi akhir hama 19, 18 dan 16 ekor pada varietas Ciherang, Inpari 32 dan IR64.
\end{abstract}

Kata kunci : Ketahanan, varietas padi, Scotinophara coarctata, kepinding tanah. 


\section{PENDAHULUAN}

Padi (Oryza sativa L.) merupakan tanaman pangan yang sangat penting di dunia setelah gandum dan jagung. Padi merupakan tanaman pangan yang sangat penting karena beras masih digunakan sebagai makanan pokok bagi sebagian besar penduduk dunia terutama Asia sampai sekarang. Beras merupakan komoditas strategis di Indonesia karena beras mempunyai pengaruh yang besar terhadap kestabilan ekonomi dan politik (Purnamaningsih, 2006).

Di kecamatan Beringin kabupaten Deli Serdang produksi padi sawah pada tahun 2013 hingga 2014 mengalami penurunan sebesar 9.874 kwintal atau penurunan produktifitas 0,3 kwintal/hektar, Hal ini dapat disebabkam oleh beberapa faktor seperti penuruan luas lahan, serangan hama dan penyakit, maupun sistem tanam yang berbeda (Hidayati, 2016).

Produksi padi sawah secara keseluruhan dipengaruhi oleh beberapa komponen produksi. Produktifitas padi sawah lebih tinggi dengan sistem tanam legowo, sistem pengairan berselang, penerapan PHT, menggunakan Varietas Unggul Baru (VUB) dan penanaman pada musim kemarau. Rendahnya produksi padi sawah pada musim hujan disebabkan oleh rendahnya radiasi surya sebagai komponen utama fotosintesis dan tingginya tingkat kelembaban yang memicu perkembangan hama dan penyakit tanaman sehingga berdampak pada produktifitas padi (Suharyanto et al. 2015).

Sedikit yang menyadari bahwa kepinding tanah $S$. coarctata yang awalnya merupakan hama minor telah menjadi salah satu hama paling merusak pada tanaman padi (Joshi et al. 2007). Perubahan teknik atau sistem pertanaman padi serta jenis varietas yang dibudidayakan secara bersamaan dapat menyebabkan hama tertentu yang dianggap sebagai hama minor pada masa sebelumnnya, dianggap sebagai hama major saat ini (Krishnaiah dan Varma, 2009).

Menurut Balai Penelitian Tanaman Penyakit dan Hama (2016) populasi kepinding tanah di Sumatera Utara mulai meningkat cukup signifikan dan diprediksi akan semakin meningkat pada tahun-tahun mendatang.

Perkembangan populasi kepinding tanah di pertanaman padi berfluktuasi dan populasinya masih tetap tinggi sampai menjelang panen (Ismawati, 2012). Hama kepinding tanah sangat aktif selama periode migrasi (bulan purnama) yang menyebabkan imago dapat terbang dan berpindah (Joshi et al. 2007).

$S$. coarctata sangat intensif menyerang pada semua tahapan pertumbuhan tanaman padi. Nimfa dan imago, menyebabkan dua jenis kerusakan, yaitu, "deadheart" kerusakan selama tahap vegetatif dan "whitehead" selama masa reproduksi (Joshi et al. 2007).

$S$. coarctata merusak tanaman dengan cara menusuk dan menghisap pangkal batang padi, sehingga pada populasi yang tinggi menyebabkan tanaman menjadi kuning atau merah kecoklatan, akhirnya layu dan mati (Kartohardjono et al.2009).

Pengisapan oleh $S$. coarctata pada fase anakan, menyebabkan jumlah anakan berkurang dan pertumbuhan terhambat atau kerdil (Deptan, 2007). Serangan hama ini mampu menyebabkan kerugian hasil $80 \%$ (Redondo et al. 2007).

Varietas yang toleran merupakan pengendalian yang diharapkan dalam meminimalkan kerusakan serangan hama kepinding tanah (Ranamukhaarachchi and Wickramasinghe, 2007).

Varietas tahan menjadi pilihan untuk pengendalian hama serangga. Ketahanan yang lebih awet (durable resistence) dengan cara menggabungkan lebih dari dua gen ketahanan, baik gen utama maupun gen minor, yang diharapkan hal ini akan mampu menghambat pembentukan biotipe baru pada hama tersebut (Iswanto et al. 2015).

Sampai saat ini masih sedikit sekali dilakukan penelitian tentang $S$. coarctata pada tanaman padi di Indonesia, baik dari aspek pengendalian maupun aspek-aspek lainnya. Adapun tujuan penelitian ini adalah untuk menentukan varietas padi sawah yang paling tahan terhadap serangan hama kepinding tanah ( $S$. coarctata). Hasil penelitian ini diharapkan dapat memberikan informasi tentang ketahanan 
beberapa varietas padi sawah terhadap kepinding tanah ( $S$. coarctata) yang dapat dijadikan sebagai acuan dalam penggunaan varietas tahan dalam pengendalian hama (S. coarctata).

Adapun tujuan penelitian ini adalah untuk menentukan varietas padi sawah yang paling tahan terhadap serangan hama kepinding tanah ( $S$. coarctata), dengan hipotesis bahwa terdapat varietas padi yang paling tahan terhadap serangan hama kepinding tanah (S. coarctata).

Hasil penelitian ini diharapkan dapat memberikan informasi tentang ketahanan beberapa varietas padi sawah terhadap kepinding tanah ( $S$. coarctata).

\section{BAHAN DAN METODE}

Penelitian dilaksanakan di Laboratorium Hama dan Rumah Kasa Fakultas Pertanian, Universitas Sumatera Utara, Medan dengan ketinggian $\pm 32 \mathrm{~m}$ di atas permukaan laut dimulai bulan Agustus sampai Desember 2017. Bahan yang digunakan dalam penelitian ini adalah $S$. coarctata, tanah sawah sebagai media tanam,benih padi varietas Ciherang, IR64 dan Inpari 32, pupuk (Urea, SP-18, dan $\mathrm{KCl}$ ), ember 22 liter, label, bambu, karung, terpal dan kain kasa untuk dijadikan sungkup dengan kerangka bambu berukuran 40 x 40 x $140 \mathrm{~cm}$. Alat yang digunakan antara lain cangkul, botol film atau pial, pinset, mistar, meteran, sabit bergerigi, timbangan, tampi, gunting, kamera, dan alat lain yang dibutuhkan dalam penelitian.

Penelitian ini menggunakan metode penelitian Rancangan Acak Kelompok (RAK) Faktorial dengan menggunakan 2 faktor yaitu Faktor I : Ciherang, IR64, dan Inpari 32 serta Faktor II : Kontrol (tidak ada $S$. coarctata), Imago $S$. coarctata sebanyak 2 pasang, Imago $S$. coarctata sebanyak 4 pasang, dan Imago S. coarctata sebanyak 6 pasang, dengan jumlah tanaman seluruhnya 48 tanaman.

Intensitas serangan kepinding tanah diamati dengan acuan rumus intensitas serangan Deptan (2007).

$$
I=\frac{\sum_{i=0}^{Z}(\text { nivi })}{Z \cdot N} \times 100 \%
$$

Secara kuantitatif, kerusakan akibat serangan hama tanaman padi dikategorikan: kerusakan ringan (intensitas serangan $<25 \%$ ), kerusakan sedang (intensitas serangan $25-50 \%$ ), kerusakan berat (intensitas serangan $50-90 \%$ ), dan kategori puso bila kerusakan $>90 \%$ (Deptan, 2007).

Persentase kehilangan hasil diambil dari persentase selisih total gabah kering panen (gkp) dengan gabah kering giling (gkg). Pengamatan populasi akhir kepinding tanah, dilakukan dengan menghitung jumlah akhir kepinding tanah pada saat panen terhadap semua kombinasi perlakuan.

\section{HASIL DAN PEMBAHASAN}

\section{Intensitas Serangan S.coarctata (\%)}

Berdasarkan hasil analisa sidik ragam pada Tabel 1 persentasi intensitas serangan menunjukkan bahwa varietas padi dan hama berpengaruh nyata terhadap intensitas serangan S. coarctata (kecuali pada kontrol).

Tabel 1. Persentasi intensitas serangan hama Scotionophara coarctata (\%)

\begin{tabular}{|c|c|c|c|c|c|}
\hline \multirow[b]{2}{*}{ Varietas } & \multicolumn{4}{|c|}{ Jumlah Hama } & \multirow[b]{2}{*}{ Rataan } \\
\hline & $\begin{array}{c}\mathrm{H} 1 \\
0 \\
\text { Pasang } \\
\end{array}$ & $\begin{array}{c}\mathrm{H} 2 \\
2 \\
\text { Pasang }\end{array}$ & $\begin{array}{c}\mathrm{H} 3 \\
4 \\
\text { Pasang }\end{array}$ & $\begin{array}{c}\mathrm{H} 4 \\
6 \\
\text { Pasang }\end{array}$ & \\
\hline ................. & $\ldots$ &..$\%$. & $\ldots \ldots$ & ...... & \\
\hline $\begin{array}{c}\text { V1 } \\
\text { (Ciherang) }\end{array}$ & $0.00 \mathrm{e}$ & $4.64 a b$ & $5.95 a$ & $4.24 b c$ & 3.71 \\
\hline $\begin{array}{c}\mathrm{V} 2 \\
\text { (IR64) }\end{array}$ & $0.00 \mathrm{e}$ & $2.71 \mathrm{~d}$ & $3.52 \mathrm{bcd}$ & $4.68 \mathrm{ab}$ & 2.73 \\
\hline $\begin{array}{c}\text { V3 } \\
\text { (Inpari 32) }\end{array}$ & $0.00 \mathrm{e}$ & $2.65 \mathrm{~d}$ & $2.98 \mathrm{~cd}$ & $4.30 \mathrm{bc}$ & 2.48 \\
\hline Rataan & 0.00 & 3.33 & 4.15 & 4.41 & 2.97 \\
\hline
\end{tabular}

Hasil intensitas serangan tertinggi terdapat pada varietas Ciherang dengan perlakuan 4 pasang $(5.95 \%)$. Pada perlakuan 6 pasang, intensitas serangan tertinggi terdapat pada varietas IR64. Pada perlakuan 6 pasang varietas Ciherang memiliki hubungan tidak berbeda nyata pada varietas Inpari 32. Berdasarkan uji lanjut, dibandingkan varietas lainnya varietas Ciherang memiliki tingkat serangan yang relatif lebih tinggi di bandingkan dengan varietas IR64 dan varietas Inpari 32. 
Menurut Hidayat et al. (2015) kerentanan suatu varietas terhadap $S$. coartata dapat di pengaruhi oleh struktur maupun morfologi tanaman itu sendiri.

Hasil pengamatan menunjukkan bahwa pada setiap rataan perlakuan intensitas serangan, varietas Ciherang menunjukkan intensitas tertinggi (3.73\%), diikuti oleh varietas IR64 (2.73\%), dan varietas Inpari 32 $(2.48 \%)$ (Tabel 1). Dengan demikian, berdasarkan skoring ketahanan tanaman, maka hasil penelitian ini menunjukkan bahwa ketiga varietas yang diuji dikategorikan pada skala 1 yaitu tahan terhadap $S$. coarctata.

\section{Populasi Akhir S.coarctata (ekor)}

Berdasarkan hasil analisa sidik ragam pada Tabel 2 populasi akhir dari S. coarctata, menunjukkan bahwa varietas padi (kecuali perlakuan kontrol) berpengaruh nyata terhadap populasi akhir S. coarctata.

Tabel 2. Rataan populasi akhir hama Scotionophara coarctata (ekor)

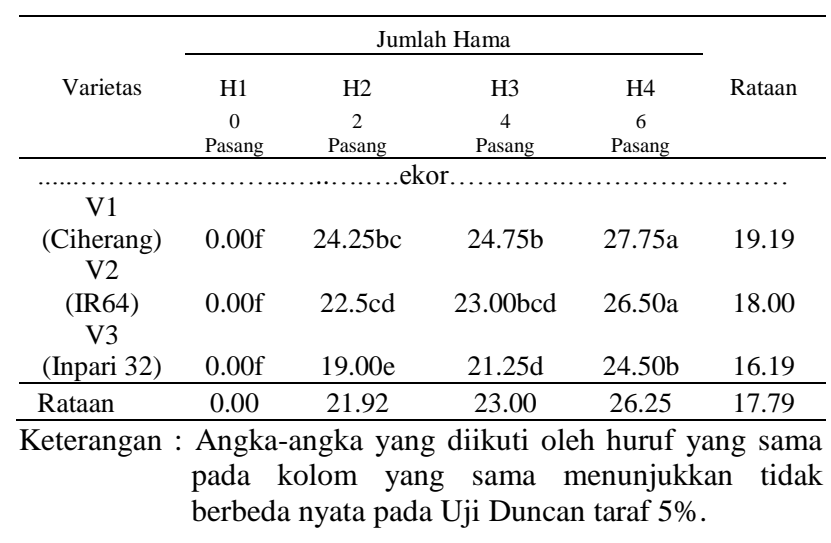

Populasi akhir S. coarctata tertinggi pada setiap rataan perlakuan varietas terdapat pada varietas Ciherang dan populasi akhir $S$. coarctata terendah terdapat pada varietas Inpari 32. Hasil pengamatan menunjukkan bahwa rataan populasi hama $S$. coarctata tertinggi terdapat pada varietas Ciherang $(19,19$ ekor), diikuti oleh varietas IR64 (18.00 ekor), dan Inpari 32 (16,19 ekor).

Perbedaan jumlah populasi $S$. coarctata dipengaruhi oleh pakan hama pada tiap varietas. Dari hasil penelitian, $S$. coarctata pada varietas Ciherang memiliki populasi $S$. coarctata lebih banyak dibandingkan dengan varietas Inpari 32. Perbedaan jumlah populasi dipengaruhi oleh banyak hal, salah satunya adalah perbedaan sumber pakan (jenis varietas). Saroinsong (2014) menyatakan bahwa semakin bertambah umur tanaman semakin tinggi populasi hama tersebut, hal ini disebabkan oleh beberapa faktor yang mempengaruhi salah satunya adalah faktor pakan. Faktor pakan merupakan faktor yang sangat mempengaruhi tingginya populasi hama $S$. coarctata karena pakan merupakan sumber gizi yang dipergunakan serangga untuk hidup dan berkembang. Jika pakan tersedia dengan kualitas yang cocok dan kuantitas yang cukup maka populasi serangga akan naik dengan cepat.

\section{Persentase Kehilangan Hasil (\%)}

Berdasarkan hasil analisa sidik ragam pada Tabel 3 persentase kehilangan hasil akhir tanaman padi terhadap $S$. coarctata, menunjukkan bahwa varietas padi dan hama berpengaruh nyata terhadap kehilangan hasil akhir S. coarctata (kecuali pada perlakuan kontrol).

Hasil pengamatan menunjukkan bahwa kehilangan hasil terbesar terdapat pada varietas Ciherang $(37,18 \%)$ dan berbeda nyata dengan varietas IR64 $(30,89 \%)$ dan varietas Inpari 32 (29,3\%). Menurut Redondo et al. (2007) kepinding tanah merupakan salah satu hama yang menyerang pada semua tahapan pertumbuhan tanaman padi, dan mampu menyebabkan kerugian hasil hingga $80 \%$ atau kerugian hasil lengkap selama infestasi berat

Tabel 3. Persentase kehilangan hasil oleh hama Scotionophara coarctata (\%)

\begin{tabular}{|c|c|c|c|c|c|}
\hline \multirow[b]{2}{*}{ Varietas } & \multicolumn{4}{|c|}{ Jumlah Hama } & \multirow[b]{2}{*}{ Rataan } \\
\hline & $\begin{array}{c}\mathrm{H} 1 \\
0 \\
\text { Pasang }\end{array}$ & $\begin{array}{c}\mathrm{H} 2 \\
2 \\
\text { Pasang }\end{array}$ & $\begin{array}{c}\mathrm{H} 3 \\
4 \\
\text { Pasang }\end{array}$ & $\begin{array}{c}\mathrm{H} 4 \\
6 \\
\text { Pasang }\end{array}$ & \\
\hline \multicolumn{6}{|c|}{ 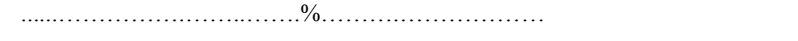 } \\
\hline $\begin{array}{c}\text { V1 } \\
\text { (Ciherang) }\end{array}$ & $16.44 \mathrm{f}$ & $41.90 \mathrm{~b}$ & $39.66 \mathrm{bc}$ & $50.73 \mathrm{a}$ & 37.18 \\
\hline $\begin{array}{r}\mathrm{V} 2 \\
(\text { IR64) }\end{array}$ & $15.83 \mathrm{f}$ & 31.08de & $36.46 \mathrm{bcd}$ & $40.18 \mathrm{bc}$ & 30.89 \\
\hline $\begin{array}{c}\text { V3 } \\
\text { (Inpari 32) }\end{array}$ & $14.99 \mathrm{f}$ & $27.00 \mathrm{e}$ & $34.74 \mathrm{~cd}$ & $40.46 \mathrm{bc}$ & 29.30 \\
\hline Rataan & 15.76 & 33.33 & 36.96 & 43.79 & 32.46 \\
\hline Keterangan & $\begin{array}{l}\text { Angka- } \\
\text { pada } \mathrm{k} \\
\text { berbeda }\end{array}$ & $\begin{array}{l}\text { ka yan } \\
\text { m yai } \\
\text { ata pad }\end{array}$ & $\begin{array}{l}\text { diikuti o } \\
\text { sama } \\
\text { Jji Dunca }\end{array}$ & $\begin{array}{l}\text { huruf } \\
\text { nunjuk } \\
\text { araf 5\% }\end{array}$ & $\begin{array}{l}\text { g sama } \\
\text { tidak }\end{array}$ \\
\hline
\end{tabular}




\section{Kriteria Ketahanan Berbagai Varietas pada Tanaman Padi}

Penetapan ketahanan tanaman padi terhadap hama $S$. coarctata dilakukan dengan menggunakan metode dari IRRI (2005) yaitu dengan nilai intensitas serangan hama pada Tabel 1.

Tabel 4 menunjukkan bahwa varietas Ciherang, IR 64 dan Inpari 32 tahan terhadap

\begin{tabular}{ccc}
\hline Varietas & Intensitas Serangan & Ketahanan \\
\hline Ciherang & 14.84 & Tahan \\
IR64 & 10.91 & Tahan \\
Inpari 32 & 9.93 & Tahan \\
\hline
\end{tabular}

serangan $S$. coarctata. Seluruh varietas yang diuji (kecuali pelakuan kontrol) mengalami serangan oleh $S$. coarctata dan dapat berkembang biak pada setiap varietas yang diberi perlakuan berbeda (kecuali perlakuan kontrol), namun varietas dikategorikan sebagai kerusakan ringan.

Kriteria ketahanan ketiga varietas yang diuji dapat dilihat pada Tabel 4.

Tabel 4. Ketahanan ketiga varietas padi terhadap $S$. coarctata

\section{SIMPULAN}

Intensitas serangan yang disebabkan oleh $S$. coarctata dari tertinggi hingga terendah yaitu varietas Ciherang (3.73\%), varietas IR64 (2.73\%), dan varietas Inpari 32 (2.48\%). Populasi akhir kepinding tanah tertinggi terdapat pada varietas Ciherang dengan perlakuan 6 pasang yaitu 27 ekor. Ketiga varietas yaitu Ciherang, IR64, dan Inpari 32 tergolong dalam skala 1 (tahan) terhadap $S$. coarctata. Kehilangan yang disebabkan oleh S. coarctata dari tertinggi hingga terendah yaitu varietas Ciherang (37.18\%), varietas IR64 (30.89\%), dan varietas Inpari 32 (29.30\%). Ketiga varietas yaitu Ciherang, IR64, dan Inpari 32 tergolong dalam skala 1 (tahan) terhadap S. coarctata.

\section{Saran}

Untuk mengurangi tingkat serangan dan kehilangan hasil dari $S$. coarctata tanpa menggunakan pestisida, tetapi menggunakan varietas Inpari 32.
Perlu dilakukan penelitian mengenai penentuan skala kerusakan pada tanaman padi oleh hama $S$. coarctata karena sampai saat ini skala kerusakan masih berdasarkan dengan skala kerusakan akibat WBC.

\section{DAFTAR PUSTAKA}

Balai Penelitian Tanaman Penyakit dan Hama. 2016. Laporan Tahunan 2010-2014 Balai Penelitian Tanaman Penyakit dan Hama. Deli Serdang.

Deptan. 2007. Pedoman Rekomendasi Pengendalian Hama Terpadu pada Tanaman Padi. Direktorat Perlindungan Tanaman Pangan. Jakarta.

Hidayat, T., M. C. Tobing., dan D. Bakti. 2015. Ketahanan beberapa varietas dan umur tanaman padi terhadap Kepinding Tanah (Scotionophara coarctata) (Hemiptera: Pentatomidae). J. Ilmu Pertanian KULTIVAR 1 (9) : 36-46.

Hidayati, T. 2016. Kecamatan Beringin Dalam Angka. Badan Pusat Statistik Deli Serdang. Sumatera Utara.

IRRI Rice Knowledge Bank, 2005. Informasi Ringkas Teknologi Padi. http://bbpadi.litbang.pertanian.go.id (Diakses pada tanggal 5 April 2017).

Ismawati. 2012. Perkembangan Populasi Kepinding Tanah

Scotinophara Coarctata (Fabricius) (Hemiptera: Pentatomidae) Pada Pertanaman Padi. Skripsi. Institut Pertanian Bogor. Bogor.

Iswanto, E.H., U. Susanto dan A. Jamil. 2015. Perkembangan dan tantangan perakitan varietas tahan dalam pengendalian Wereng Cokelat di Indonesia. Jurnal Penelitian dan Pengembangan Pertanian. 34:4 (187-193).

Joshi, R. C., T. Alberto., Barrion and S. S. Leocadio. 2007. Rice black bugs: taxonomy, ecology, and management of invasive species. Science City of Muñoz, Nueva Ecija. Philippines Rice Research Institute. Philippines.

Kartohardjono, K., D. Kertoseputro dan T. Suryana. 2009. Hama Padi Potensial dan Pengendaliannya. Balai Besar Penelitian Tanaman

Padi. 
http://bbpadi.litbang.pertanian.go.id

(Diakses pada tanggal 29 Maret 2017).

Krisnaiah, K., dan N. R. G. Varma. 2009.

Changing Insect Pest Scenario in the Rice

Ecosystem A National Perspective.

Fomer Project Director. Directorate of

Rice Research Rejendranagar.

Hyderabad. India.

Purnamaningsih, R. 2006. Induksi kalus dan optimasi regenerasi empat varietas padi melalui kultur in vitro. J. Agrobio. 2(2):74-80.

Ranamukhaarachchi, S. L., and S. Wickramasinghe. 2007. Biology, Ecology, and Management of Rice Black Bugs in Some Asian Countries. Department of Biological Science, Faculty of Applied Sciences, University of Sri Lanka, Sri Lanka.

Redondo, O., Guadalupe, Cheryll, C. Launio and Rowena. 2007. Farmer's Knowledge, Perceptions and Management Practices on Rice Black Bug. Philippines Rice Research Institute. Philippines.

Saroinsong, R., S. 2014. Inventarisasi JenisJenis Hama Pada Pertanaman Cabai (Capsicum annum) di Kelurahan Kakaskasen I Kota Tomohon. Skripsi. Fakultas Pertanian Universitas Sam Ratulangi. Manado.

Suharyanto, H., Jangkung., H. Dwidjono., Darwanto dan S. Widodo. 2015. Analisis Produksi dan Efisiensi Pengelolaan Tanaman Terpadu Padi Sawah di Provinsi Bali. Balai Pengkajian Teknologi Pertanian (BPTP) Bali. Bali. 